\title{
OPEN MODELS AND SOFTWARE FOR ASSESSING THE VULNERABILITY OF THE EUROPEAN BUILDING STOCK
}

\author{
Helen Crowley ${ }^{1}$, Vitor Silva², Luis Martins ${ }^{2}$, Xavier Romão ${ }^{3}$ and Nuno Pereira ${ }^{3}$ \\ ${ }^{1}$ EUCENTRE \\ Via Ferrata 1, Pavia 27100, Italy \\ e-mail: helen.crowley@eucentre.it \\ ${ }^{2}$ GEM Foundation \\ Via Ferrata 1, Pavia 27100, Italy \\ vitor.silva@globalquakemodel.org, luis.martins@globalquakemodel.org \\ ${ }^{3}$ University of Porto \\ Rua Dr. Roberto Fria, 4200-465 Porto, Portugal \\ xnr@fe.up.pt, nmsp@fe.up.pt
}

\begin{abstract}
Reproducibility and transparency have become standard practice in earthquake loss modelling following a growing demand from both the public and private sectors for understandable and accessible risk model input data, software and results. Since the 1990's the European scientific community has worked together on many aspects of seismic hazard and risk modelling. These advances have led to the 2020 European Seismic Risk Model (ESRM20), which has been computed with open source software and is now being openly released to the wider scientific community. This paper presents the recently released input models and software to assess the vulnerability of the European building stock within ESRM20.
\end{abstract}

Keywords: Vulnerability, Fragility, European Exposure, Open-Source, Open Data.

ISSN:2623-3347 @ 2021 The Authors. Published by Eccomas Proceedia.

Peer-review under responsibility of the organizing committee of COMPDYN 2021.

doi: $10.7712 / 120121.8666 .19367$ 


\section{INTRODUCTION}

Reproducibility and transparency have become standard practice in earthquake loss modelling following a growing demand from both the public and private sectors for understandable and accessible risk model input data, software and results. Since the 1990's the European scientific community has worked together on many aspects of seismic hazard and risk modelling. These advances have led to the 2020 European Seismic Risk Model (ESRM20), which has been computed with open source software and is now being openly released to the wider scientific community (Crowley et al., 2019 [1]). This paper summarises the recently released input models and software to assess the vulnerability of the European building stock within ESRM20.

\section{CAPACITY CURVES FOR EUROPEAN BUILDING STOCK}

Capacity curves provide a description of the lateral strength and deformation capacity of buildings or building classes, and are often transformed to the ADRS (acceleration displacement response spectrum) format for the purposes of developing fragility functions.

For ESRM20, capacity curves for a large range of building classes are needed to cover the varying construction types in Europe (as included within the European exposure model: Crowley et al., 2020a [2]; Crowley et al., 2020b [3]). The GED4ALL Building Taxonomy has been used to classify the vulnerability of European buildings (Brzev et al., 2021 [4]) with the attributes summarised below:

- Materials. CR: reinforced concrete, MR: reinforced masonry, MCF: confined masonry, MUR: unreinforced masonry, MUR-ADO: adobe, MUR-CB99: concrete block masonry, MUR-CL99: clay brick masonry, MUR-STDRE: dressed stone masonry, MUR-STRUB: rubble stone masonry, S: steel, W: wood/timber.

- Lateral load resisting systems. LDUAL: dual frame-wall system, LFINF: infilled frame, LWAL: load bearing wall, LFM: moment frame, LFBR: braced frame.

- Code Level or Ductility. CDN: absence of seismic design, CDL: low code level (designed for lateral resistance using allowable stress design), CDM: moderate code level (designed for lateral resistance with modern limit state design), $\mathrm{CDH}$ : high code level (designed for lateral resistance coupled with target ductility requirements and capacity design), DNO: non-ductile, DUL: low ductility, DUM: moderate ductility, DUH: high ductility.

- Height. H: number of storeys.

- Lateral Force Coefficient. The value of the lateral force coefficient, i.e. the fraction of the weight that was specified as the design lateral force in the seismic design code (see Code Level), expressed in \% (applied to reinforced concrete moment and infilled frames only).

Following their use in the calculation of their Global Seismic Risk Map (GEM, 2018), the GEM Foundation has released a global database of capacity curves (Martins and Silva, 2020 [5]) which have been derived through the compilation of data coming from research studies and experimental campaigns. These capacity curves have been used to represent the European CR_LDUAL, CR_LWAL, MCF, MR, MUR, S and W typologies with different heights and ductility, for a total of 217 building classes.

As part of the European SERA project (www.sera-eu.org), a detailed set of capacity curves for European reinforced concrete infilled frames (CR_LFINF) and moment frames (CR_LFM) has been recently developed (Romão et al., 2019 [6]). A total of 264 reinforced concrete classes have been identified by combining different numbers of storeys (1 to 6), seismic design code levels (no code: $\mathrm{CDN}$, low code: $\mathrm{CDL}$, moderate code: $\mathrm{CDM}$, high code: $\mathrm{CDH}$ ) and lateral force coefficient levels $(0,5,10,15,20,25,30 \%$ of the weight of the structure). Buildings of 
design class CDN were typically designed to older codes (from before the 1960's) that used allowable stresses and very low material strength values and considered predominantly the gravity loads. Buildings of design class CDL were designed considering the seismic action by enforcing values of the seismic coefficient, $\beta$ (referred to herein as lateral force coefficient). Structural design for these codes was typically based on material-specific standards that used allowable stress design or a stress-block approach. Seismic design including modern concepts of ultimate capacity and partial safety factors (limit state design) was the basis of the CDM category of codes. The seismic action was also accounted for in the design by enforcing values for the lateral force coefficient, $\beta$. Finally, the $\mathrm{CDH}$ class refers to modern seismic design principles that account for capacity design and local ductility measures, similar to those available in Eurocode 8 (CEN, 2004 [7]). Seismic zonation maps associated with the seismic design codes employed in Europe over the last century can be used to identify the lateral force coefficient (i.e. the fraction of the weight that was specified as the design lateral force in the seismic design code, expressed in \%) (see Crowley et al., 2021 [2] and Crowley et al., 2020c [9]).

The capacity curves for the 264 building classes were developed through simulated design of prototype frames (see e.g. Borzi et al., 2008 [10]; Verderame et al., 2010 [11]) and then nonlinear analysis has been undertaken to obtain the backbone capacity curves of these frames. Up to 300 capacity curves have been simulated per class by modifying the geometrical and material properties of the prototype frames, and thus accounting for the building-to-building variability in the simulated design. Figure 1 shows the median capacity curves for reinforced concrete frames with masonry infills not designed with seismic loads (CDN).

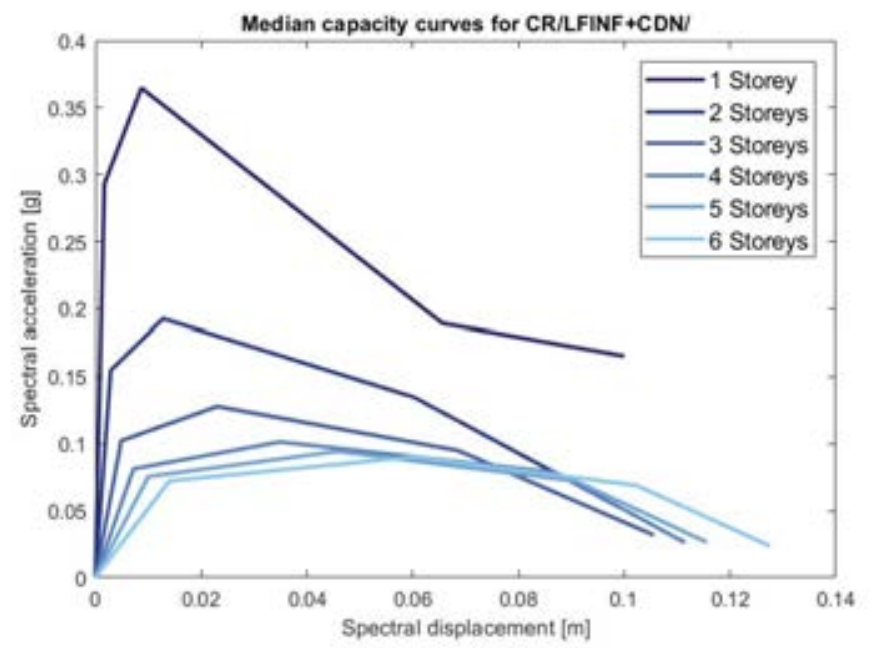

Figure 1: Median capacity curves from Romão et al. (2020) [12] for reinforced concrete frames with masonry infills (CR/LFINF) not designed with seismic loads (CDN)

All of the median capacity curves for the 481 building classes are publicly available on a GitLab repository (Romão et al. 2020 [12]).

\section{VULNERABILITY MODELLING}

\subsection{Vulnerability Modellers' Toolkit (VMTK)}

The fragility functions of these European building classes have been computed using the Vulnerability Modeller's Toolkit, a resource that has been developed and released by the GEM Foundation in collaboration with members of the European risk community (Martins et al., 2021 [13]). This toolkit is a set of Python scripts that read the capacity curves, produce SDOF 
hysteretic models, launch OpenSeesPy ${ }^{1}$ to run nonlinear dynamic analysis, apply linear censored regression to the cloud of nonlinear responses, and compute fragility functions for different damage states, based on the user-defined damage state thresholds. A graphical user interface is included with the toolkit and includes a set of default assumptions, allowing less experienced users to interact with the VMTK (Figure 2). Experienced users are instead encouraged to make use of Python's scripting capabilities to explore all the features of the VMTK source code and to contribute to future releases of the toolkit. The complete toolkit, including source code and GUI, is currently hosted in a publicly available GitHub repository².

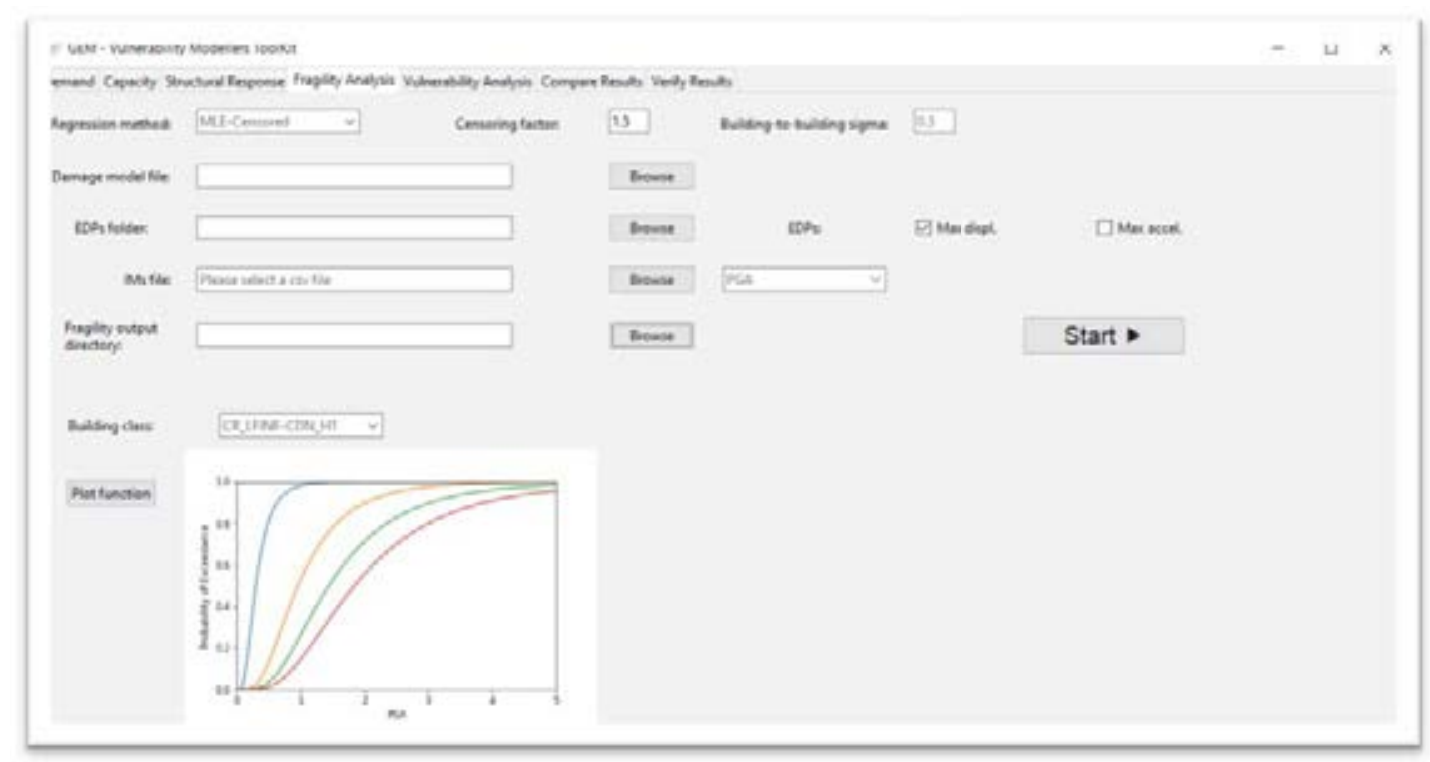

Figure 2: Graphical user interface of the fragility module of the VMTK (Martins et al., 2021 [13])

\subsection{Fragility Functions}

The median capacity curves in Romão et al. 2020 [12] have been read by the VMTK's 'nlth_on_sdof.py' script which has been used to produce SDOF models using the Pinching4 hyseresis curve of OpenSeesPy. Pinghing4 is a uniaxial material that represents a 'pinched' load-deformation response and exhibits degradation under cyclic loading. In addition to the response envelope (taken from the capacity curves), the hysteretic properties given in Table 1 have been assumed for the SDOF models for the different material types. Cyclic degradation of the strength and stiffness is modelled for the CR, MUR, MCF and MR typologies through unloading stiffness degradation, reloading stiffness degradation, and strength degradation. Mass proportional damping is used with different damping ratios for each typology. Typically, masonry is assigned $10 \%$ damping, reinforced concrete and wood is $5 \%$, and steel is $3 \%$. The nlth_on_sdof.py' script runs nonlinear dynamic analysis using each SDOF and a set of records. A database of recordings has been compiled for the nonlinear dynamic analyses using records with PGA above 0.05g in the Engineering Strong Motion (ESM, Luzi et al 2016 [14]; Luzi et al. 2020 [15]) and NGA (Chiou et al. 2008 [16]) databases. Records have then been selected from this database to match a range of intensity measure bins with a maximum scaling factor of 2 .

\footnotetext{
${ }^{1}$ https://openseespydoc.readthedocs.io/en/latest/index.html

2 https://github.com/GEMScienceTools/VMTK-Vulnerability-Modellers-ToolKit
} 
The SDOF properties reported above are currently being further tested and modifications might still be incorporated in the final European fragility models. The final scripts used to develop the models will be made available on the aforementioned GitLab repository (Romão et al. 2020 [12]) so that are final assumptions are transparent and it will be possible to easily reproduce the models.

Table 1: Adopted parameters of the Pinching4 hyseresis model

\begin{tabular}{ccc}
\hline Parameters of Pinching4* & CR, MUR, MCF, MR & W, S \\
\hline rdispP/N, fForceP/N, uForceP/N & $0.5,0.25,0.05$ & $0.5,0.25,0.5$ \\
gK1 gK2 gK3 gK4 gKLim & $0,0.1,0,0,0.2$ & $0,0,0,0,0$ \\
gD1 gD2 gD3 gD4 gDLim & $0,0.1,0,0,0.2$ & $0,0,0,0,0$ \\
gF1 gF2 gF3 gF4 gFLim & $0,0.4,0,0.4,0.9$ & $0,0,0,0,0$ \\
gE & 10 & 10 \\
dmgType & energy & energy \\
\hline
\end{tabular}

* See https://openseespydoc.readthedocs.io/en/latest/src/Pinching4.html?highlight=pinching4 for definition of the parameters

The 'fragility_censored_cloud_analysis.py' script in the VMTK uses the nonlinear response outputs from each dynamic analysis together with damage thresholds to apply linear censored regression, and this is then used to compute fragility functions (lognormal distributions) for different damage states, based on the user-defined damage state thresholds. For the European fragility functions, the damage thresholds presented in Figure 3 have been assumed.

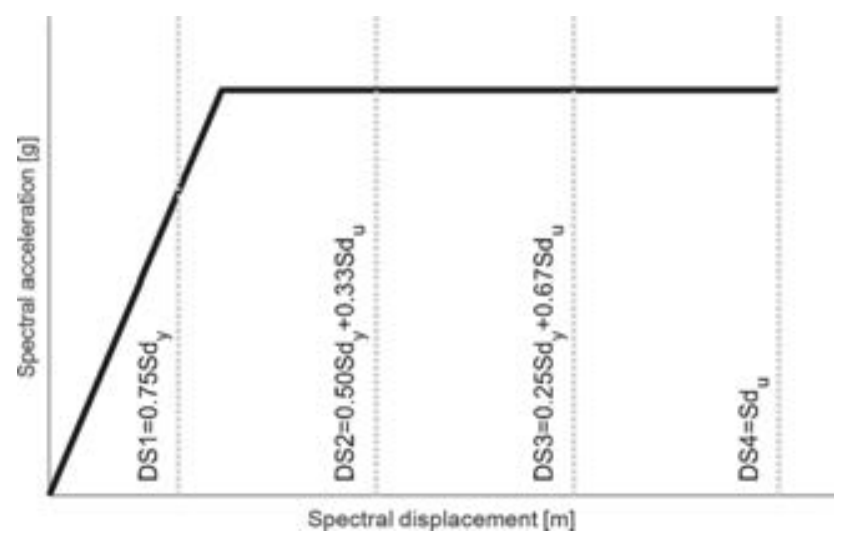

Figure 3: Damage thresholds assumed in the development of the fragility functions (Martins and Silva, 2020 [8])

Four different intensity measure types have been used in the censored regression: PGA, Sa(0.3), $\mathrm{Sa}(0.6)$ and $\mathrm{Sa}(1.0)$. An average spectral acceleration (see e.g. Baker and Cornell (2006) [17]; Eads et al., 2015 [18]) with 20 intervals between 0.05 and 3 seconds is also currently being investigated. The final intensity measure for each building typology is taken as that with the lowest lognormal dispersion in the fragility function given that this is related to efficiency (i.e. low dispersion in the nonlinear response, given the intensity measure), and it has been found by checking the sufficiency (i.e. conditional independence of the distribution of nonlinear response, given IM, on other parameters of the ground motion) of the different intensity measures that the most efficient is typically also sufficient. Some recent studies have shown that the higher the efficiency, the higher the sufficiency of the intensity measure (e.g. Bradley et al. 2010 [19]). Others have cautioned that the typical checks for sufficiency (e.g. Luco and Cornell, 2007 [20]) only provide evidence rather than proof of sufficiency and that it should be ensured 
that the intensity measure is also efficient to ensure that the additional parameters really are having a significant influence on the response (Kazantzi and Vamvatsikos, 2015 [21]). For illustration purposes, Figure 4 shows the fragility functions in terms of $\mathrm{Sa}(0.3 \mathrm{~s})$ that have been obtained with the capacity curves presented in Figure 1.
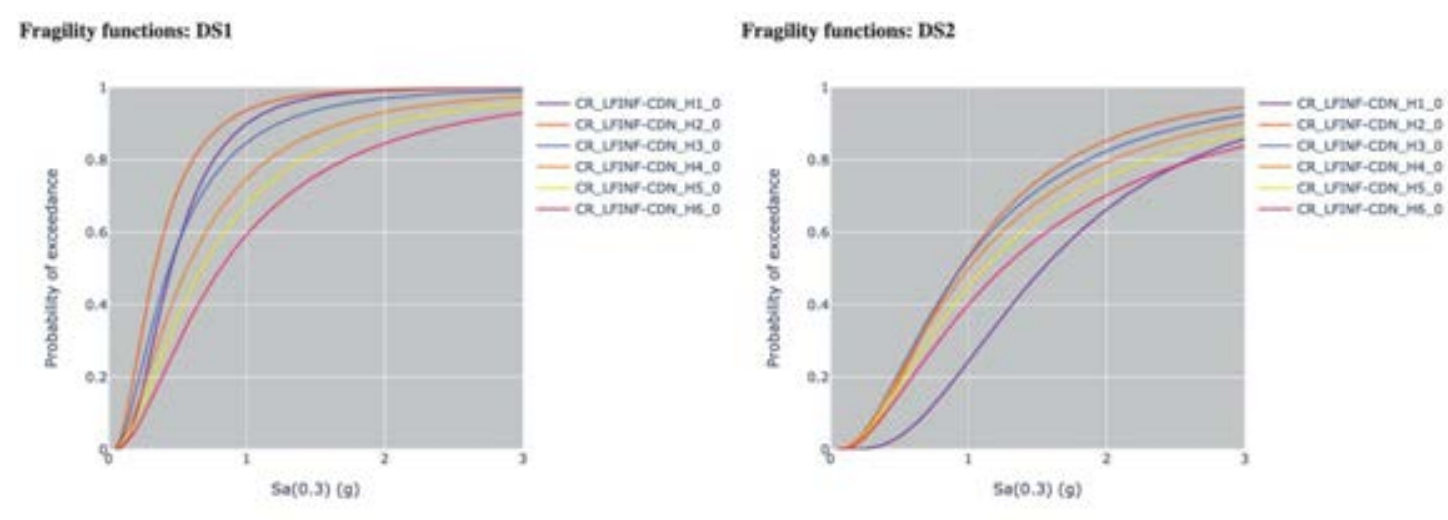

Fragility functions: DS3

Fraglity functions: DS4
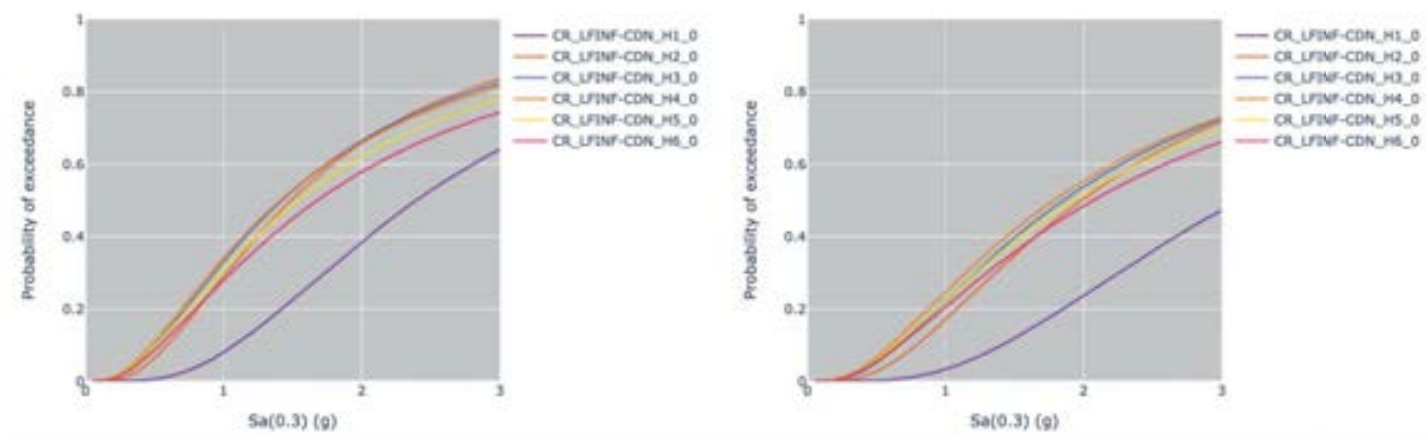

Figure 4: Fragility functions calculated using the capacity curves presented in Figure 1, where DS1 = slight damage, DS2 = moderate damage, DS3 = extensive damage and DS4 = complete damage

\subsection{Vulnerability functions for cost of repair/replacement}

The fragility functions are converted into vulnerability models using damage-loss models which provide damage ratios for each damage state (slight, moderate, extensive and complete). For losses due to the repair of damage, the damage ratios (which represent the ratio of cost of repair to cost of replacement) from HAZUS (FEMA, 2004 [22]) are being adopted, i.e. 0.02 (slight damage), 0.1 (moderate damage), 0.5 (extensive damage), 1.0 (complete damage). These values are being further tested and calibrated using the results of the tests described in Section 4 and may be adapted before the final release of ESRM20. For a range of intensity measure levels, the probability of occurrence of each damage state is obtained from the fragility functions, multiplied by the damage ratios and summed leading to a mean loss ratio. A lognormal cumulative distribution function has then been fit to the vulnerability data to obtain the median and lognormal standard deviation (dispersion).

In order to account for the building-to-building variability, which is not accounted for given the use of the median capacity curves, a separate study to produce vulnerability functions using all available capacity curves for the CR/LFINF and CR/LFM typologies has been undertaken. This study showed that the mean vulnerability function based on all of the capacity curves of a given typology had a very similar median to the vulnerability function based on the median capacity curves. However, the dispersion was, as expected, slightly higher. It was found that the additional dispersion required to account for building-to-building variability was around 0.3 , 
and this is therefore combined with the dispersion obtained with the median capacity curves through the square-root-sum-of-squares to produce the final vulnerability functions.

\subsection{Vulnerability functions for loss of life}

For loss of life, the model uses a number of factors obtained from both past observations and expert judgment, including the likelihood that a completely damaged building will collapse to the extent that it could cause loss of life (currently taken as $1.5 \%$ based on the data from recent earthquakes: Antonios Pomonis, personal communication), the probability of entrapment given collapse (Reinoso et al. 2017 [23]), and the probability of loss of life given entrapment (Reinoso et al. 2017 [23]). Different entrapment ratio for day and night are assumed, with higher values for the latter given the increased time required for people to wake up and escape from the collapsing building. Also, an increase in the entrapment ratio with number of storeys has been implemented for the day-time entrapment rates. The loss of life given entrapment has been obtained from the data in Table 2 of Reinoso et al. (2017 [23]) with a clear distinction between buildings with less than and more than 5 storeys being observed and thus applied. Table 2 presents all of the assumed values.

Table 2: Adopted fatality model input parameters

\begin{tabular}{llll}
\hline Number of storeys & P-entrapment (day) & P-entrapment (night) & P-loss-life|entrapment \\
\hline 1 & 0.25 & 0.95 & 0.4 \\
2 & 0.5 & 0.95 & 0.4 \\
$3-4$ & 0.75 & 0.95 & 0.4 \\
$>5$ & 0.95 & 0.95 & 0.7 \\
\hline
\end{tabular}

The fatality vulnerability models are obtained by multiplying the complete damage fragility functions by $1.5 \%$ and the factors presented in Table 2 . A lognormal function is then fit to the data and the dispersion is increased to account for building-to-building variability (as presented in the previous section).

\subsection{Vulnerability Viewer}

A Dash App is currently under development to allow users to view and compare the fragility and vulnerability functions for all of building classes and for all the available intensity measure types. A prototype that presents the vulnerability functions in terms of $\mathrm{Sa}(0.3)$ is currently available at http://vulncurves.eu-risk.eucentre.it/ (see Figure 5). 


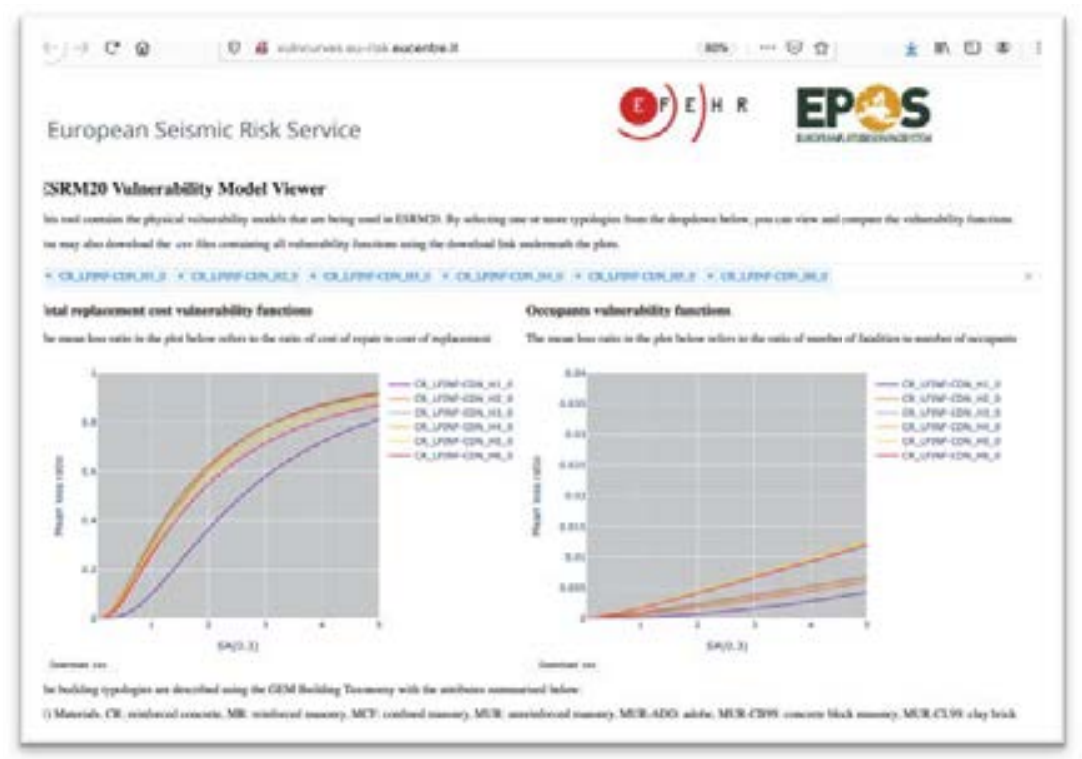

Figure 5: Screenshot of the vulnerability viewer currently under development

\section{VULNERABILITY TESTING}

Extensive testing of the resulting fragility and vulnerability models has been undertaken by comparing the modelled damage/losses with empirical models as well as with observations from a large number of past European earthquake scenarios (Crowley et al. 2020d [24]).

Simple sanity checks, so-called 'unit tests' are undertaken to ensure the median and dispersion values are within sensible ranges, and to compare with existing functions from the literature. The VMTK includes a module that allows users to test their model's against GEM's global vulnerability models, which have been calibrated or tested using past earthquake damage and loss data. Useful, and openly available, data for this purpose includes the empirical vulnerability models developed by PAGER (Jaiswal et al., 2009 [25]; Jaiswal and Wald, 2013 [26]), as well as fatality, economic loss and damage data from various databases including the Centre for Research on the Epidemiology of Disasters (CRED)'s EMDAT data-base (EMDAT, 2019 [27]), the Italian Department of Civil Protection's Da.D.O. data-base (Dolce et al., 2019 [28]), NOAA's Significant Earthquake Database (NGDC/WGS), and the Cambridge Earthquake Impact Database (www.ceqid.org).

Figure 6 shows two examples of tests that have been undertaken with the European vulnerability model. In the first example, a mean vulnerability function calculated through an exposure-weighted combination of all the building classes in the country has been produced and compared with the empirical models developed by PAGER, following conversion of the spectral ordinates to macroseismic intensity (with the associated uncertainty in the conversion shown by the mean and $+/ 1$ standard deviation vulnerability curves). In the second example, ground motion fields (modelled using scenario rupture models and the latest European ground motion and site amplification models) have been developed for over 30 damaging historical events above magnitude 5 in Europe since the 1980's. These ground motions are then combined with the current exposure and vulnerability models to estimate direct economic losses. These are then compared in a statistical sense with the reports on economic losses (that are corrected to today's value). Similar tests can also be undertaken for fatalities These tests provide a check to ensure that probabilistic losses predicted by the risk model are not biased. 

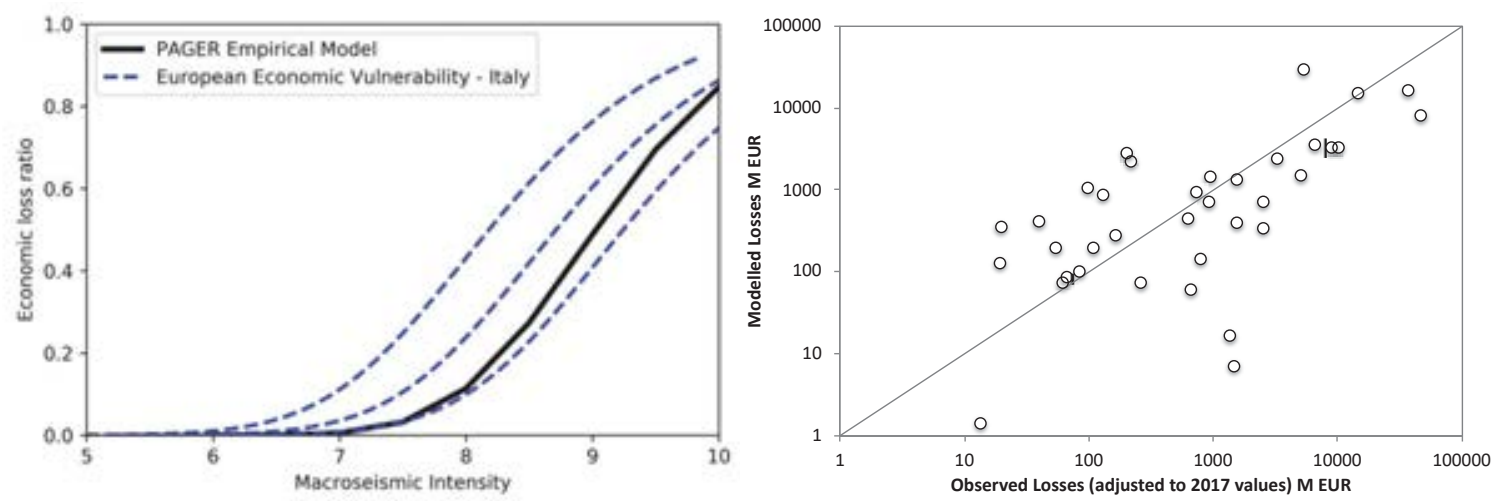

Figure 6: Example tests of the European vulnerability model: (left) comparison with the PAGER vulnerability model, where the three blue dashed lines represent the mean and +/- sigma, (right) comparison of estimated and observed losses for damaging European events since 1980

These tests will continue to be undertaken until the finalization and release of ESRM20 which is expected in October 2021. As mentioned previously, all of the scripts and input data described herein will then be released on the dedicated vulnerability GitLab repository (Romão et al. 2020 [12]).

\section{REFERENCES}

[1] H. Crowley, D. Rodrigues, V. Silva, V. Despotaki, L. Martins, X. Romão, J.M. Castro, N. Pereira, A. Pomonis, A. Lemoine, A. Roullé, B. Tourlière, G. Weatherill, K. Pitilakis, L. Danciu, A.A. Correira, S. Akkar, U. Hancilar, P. Covi, The European Seismic Risk model 2020 (ESRM20). 2nd International Conference on Natural Hazards and Infrastructure, ICONHIC, Chania, Crete, Greece, 2019.

[2] H. Crowley, V. Despotaki, D. Rodrigues, V. Silva, D. Toma-Danila, E. Riga, A. Karatzetzou, S. Fotopoulou, Z. Zugic, L. Sousa, S. Ozcebe, P. Gamba, Exposure model for European seismic risk assessment, Earthquake Spectra, DOI: https://doi.org/10.1177/8755293020919429, 2020a.

[3] H. Crowley, V. Despotaki, D. Rodrigues, V. Silva, C. Costa, D. Toma-Danila, E. Riga, A. Karatzetzou, S. Fotopoulou, L. Sousa, S. Ozcebe, P. Gamba, J. Dabbeek, X. Romão, N. Pereira, J. M. Castro, J. Daniell, E. Veliu, H. Bilgin, C. Adam, M. Deyanova, N. Ademović, J. Atalic, B. Bessason, V. Shendova, A. Tiganescu, D. Toma-Danila, Z. Zugic, S. Akkar, U. Hancilar, Exposure Contributors, European Exposure Model Data Repository (Version 0.9) [Data set]. Zenodo. DOI: http://doi.org/10.5281/zenodo.4062044, 2020 b.

[4] S. Brzev, V. Silva, L. Allen, C. Scawthorn, C. Yepes, J. Dabbeek, H. Crowley, A building classification scheme for multi-hazard risk assessment. Submitted to Natural Hazards and Earthquake System Sciences, 2021.

[5] GEM, Global earthquake maps. Available at: www.globalquakemodel.org/gem (accessed 21 March 2021), 2018.

[6] X. Romão, N. Pereira, J. M. Castro, F. De Maio, H. Crowley, V. Silva, L. Martins, European physical vulnerability models. SERA Deliverable D26.5, Available from URL: http://static.seismo.ethz.ch/SERA/JRA/SERA D26.5 Physical Vulnerability.pdf, 2019. 
[7] CEN, Eurocode 8: Design of structures for earthquake resistance - Part 1: General rules, seismic actions and rules for buildings. Comité Européen de normalization, Brussels, Belgium, 2004.

[8] L. Martins, V. Silva, Development of a fragility and vulnerability model for global seismic risk analyses. Bulletin of Earthquake Engineering, https://doi.org/10.1007/s10518020-00885-1, 2020.

[9] H. Crowley, V. Despotaki, V. Silva, J. Dabbeek, X. Romão, N. Pereira, J.M. Castro, J. Daniell, E. Veliu, H. Bilgin, C. Adam, M. Deyanova, N. Ademović, J. Atalic, E. Riga, A. Karatzetzou, B. Bessason, V. Sendova, D. Toma-Danila, Z. Zugic, S. Akkar, U. Hancilar, Model of Seismic Design Lateral Force Levels for the Existing Reinforced Concrete European Building Stock. Bulletin of Earthquake Engineering, in press, 2020d.

[10] B. Borzi, H. Crowley, R. Pinho, Simplified pushover-based vulnerability analysis for large-scale assessment of RC buildings. Engineering Structures, 30, 804-820, 2008.

[11] G.M. Verderame, M. Polese, C. Marinello, G. Manfredi, A simulated design procedure for the assessment of seismic capacity of existing reinforced concrete buildings. Advances in Engineering Software, 41(2), 323- 335, 2010.

[12] X. Romão, N. Pereira, J. M. Castro, F. De Maio, H. Crowley, V. Silva, L. Martins, European Building Vulnerability Data Repository (Version v1.1) [Data set]. Zenodo. http://doi.org/10.5281/zenodo.4087810, 2020.

[13] L. Martins, V. Silva, H. Crowley, F. Cavalieri, Vulnerability Modeller's Toolkit, an Open-Source Platform for Vulnerability Analysis. Computers \& Structures, submitted.

[14] L. Luzi, R. Puglia, E. Russo, M. D'Amico, C. Felicetta, F. Pacor, G. Lanzano, U. Çeken, J. Clinton, G. Costa, L. Duni, E. Farzanegan, P. Gueguen, C. Ionescu, I. Kalogeras, H. Özener, D. Pesaresi, R. Sleeman, A. Strollo, M. Zare, The Engineering Strong-Motion Database: A Platform to Access Pan-European Accelerometric Data. Seismological Research Letters, 87(4): p. 987-997. DOI: 10.1785/0220150278, 2016.

[15] L. Luzi, G. Lanzano, C. Felicetta, M.C. D’Amico, E. Russo, S. Sgobba, F. Pacor, ORFEUS Working Group 5, Engineering Strong Motion Database (ESM) (Version 2.0). Istituto Nazionale di Geofisica e Vulcanologia (INGV) DOI: https://doi.org/10.13127/ESM, 2020.

[16] B. Chiou, R. Darragh, N. Gregor, W. Silva, NGA project strong-motion database. Earthquake Spectra, 24, 23-44, 2008.

[17] J.W. Baker, C.A. Cornell, Spectral shape, epsilon and record selection. Earthquake Engineering \& Structural Dynamics, 35(9), 1077-1095, DOI: https://doi.org/10.1002/eqe.571, 2006.

[18] L. Eads, E. Miranda, D.G. Lignos, Average spectral acceleration as an intensity measure for collapse risk assessment. Earthquake Engineering \& Structural Dynamics, 44(12), 2057-2073, DOI: doi:10.1002/eqe.2575, 2015.

[19] B.A. Bradley, R.P. Dhakal, G.A. MacRae, M. Cubrinovski, Prediction of spatially distributed seismic demands in specific structures: Ground motion and structural response. Earthquake Engineering and Structural Dynamics, 39, 501-520, 2010.

[20] N. Luco, A. Cornell, Structure-Specific Scalar Intensity Measures for Near-Source and Ordinary Earthquake Ground Motions. Earthquake Spectra, 23(2), 357-392, 2007. 
[21] A.K. Kazantzi, D. Vamvatsikos, Intensity measure selection for vulnerability studies of building classes. Earthquake Engineering and Structural Dynamics, 44, 2677-2694, 2015.

[22] FEMA, HAZUS-MH Technical Manual, Federal Emergency Management Agency, Washington DC, 2004.

[23] E. Reinoso, M.A. Jaimes, L. Esteva, Estimation of life vulnerability inside buildings during earthquakes. Structure and Infrastructure Engineering, DOI: 10.1080/15732479.2017.1401097, 2017.

[24] H. Crowley, V. Silva, P. Kalakonas, L. Martins, G. Weatherill, K. Pitilakis, E. Riga, B. Borzi, M. Faravelli, Verification of the European Seismic Risk Model (ESRM20). Proceedings of 17th World Conference on Earthquake Engineering, Sendai, Japan, 2020d.

[25] K. Jaiswal, D. Wald, M. Hearne, Estimating casualties for large worldwide earthquakes using an empirical approach. US Geological Survey Open-File Report 1136, 2009.

[26] K. Jaiswal, D. Wald, Estimating Economic Losses from Earthquakes Using an Empirical Approach. Earthquake Spectra, 29(1), 309-324, 2013.

[27] EMDAT, International Disasters Database of the Centre for Research on the Epidemiology of Disasters. Available at https://www.emdat.be/ 2019.

[28] M. Dolce, E. Speranza, F. Giordano, B. Borzi, F. Bocchi, C. Conte, A. Di Meo, M. Faravelli, V. Pascale, Observed damage database of past Italian earthquakes: the Da.D.O WebGIS. Bollettino di Geofisica Teorica ed Applicata, 60(2), 141-164, DOI: 10.4430/bgta0254, 2019. 